\title{
IgG glycan hydrolysis by EndoS inhibits experimental autoimmune encephalomyelitis
}

\author{
Mahdia Benkhoucha ${ }^{1,2 \dagger}$, Nicolas Molnarfi ${ }^{1,2 \dagger}$, Marie-Laure Santiago-Raber ${ }^{1}$, Martin S Weber ${ }^{3}$, Doron Merkler ${ }^{1,4,5}$, \\ Mattias Collin ${ }^{6}$ and Patrice $\mathrm{H}$ Lalive $\mathrm{e}^{1,2,7^{*}}$
}

\begin{abstract}
Studies in experimental autoimmune encephalomyelitis (EAE), a mouse model of multiple sclerosis, have shown that B cells markedly influence the course of the disease, although whether their effects are protective or pathological is a matter of debate. EndoS hydrolysis of the lgG glycan has profound effects on IgG effector functions, such as complement activation and Fc receptor binding, suggesting that the enzyme could be used as an immunomodulatory therapeutic agent against lgG-mediated diseases. We demonstrate here that EndoS has a protective effect in myelin oligodendrocyte glycoprotein peptide amino acid 35-55 (MOG $35-55$ )-induced EAE, a chronic neuroinflammatory demyelinating disorder of the central nervous system (CNS) in which humoral immune responses are thought to play only a minor role. EndoS treatment in chronic MOG $35-55$-EAE did not impair encephalitogenic T cell priming and recruitment into the CNS of mice, consistent with a primary role of EndoS in controlling IgG effector functions. In contrast, reduced EAE severity coincided with poor serum complement activation and deposition within the spinal cord, suggesting that EndoS treatment impairs B cell effector function. These results identify EndoS as a potential therapeutic agent against antibody-mediated CNS autoimmune disorders.
\end{abstract}

\section{Introduction}

Multiple sclerosis (MS) is a chronic inflammatory disease of the central nervous system (CNS) characterized by immune cell infiltration into the white matter, which in turn produces demyelination, axonal damage, and the neuronal loss that is considered the main cause of permanent neurological deficits. The concept of MS as a purely T-cell-driven autoimmune disease has been challenged by recent studies indicating an important role for $\mathrm{B}$ cells in the pathogenesis of the disease [1]. Several key findings suggest a pathogenic role for B cells and antibodies in MS, mainly in association with antibody deposition and complement activation. Intrathecal immunoglobulin G (IgG) synthesis and oligoclonal bands are found in more than $90 \%$ of MS patients [2], clonally expanded B cells accumulate

\footnotetext{
* Correspondence: patrice.lalive@hcuge.ch

${ }^{\dagger}$ Equal contributors

'Department of Pathology and Immunology, Faculty of Medicine, University of Geneva, 1211, Geneva, Switzerland

${ }^{2}$ Department of Clinical Neurosciences, Division of Neurology, Unit of

Neuroimmunology and Multiple Sclerosis, Geneva University Hospital, 1211

Geneva, Switzerland

Full list of author information is available at the end of the article
}

in chronic MS lesions and in the CSF of MS patients [3], and B-cell follicle-like structures in the meninges of patients have been identified by histopathology [4]. The results of histopathological analyses indicate that antibodies might have an important role in plaque initiation and demyelination in patients with established MS [5,6]. While the antigen target of these antibodies has yet to be identified [7-11], the presence of intrathecal anti-myelin Ig has been associated with rapid disease progression $[1,12]$.

Experimental autoimmune encephalomyelitis (EAE) in mice closely mimics the inflammatory infiltration, neurological paralytic symptoms, and demyelination observed in MS. In recent studies, the EAE model has been critical in dissecting the different roles that B cells play in the regulation of MS, and has led to new insights into B cell functions in human pathogenesis and a focus on the development of B cell therapeutics. $B$ cell depletion therapy has recently been examined in EAE induced by myelin oligodendrocyte glycoprotein amino acid 35-55 (MOG $35-55)$, and confirmed that both protective and pathological B cell functions markedly

\section{Biomed Central}


influence the course of disease [13-16]. Previous studies indicated that congenitally $B$ cell-deficient mice and CD19-deficient mice with reduced B cell function develop a severe non-remitting form of $\mathrm{MOG}_{35-55^{-}}$ induced EAE [17], suggesting a regulatory role for B cells, most likely in association with the production of IL-10 [14,17]. However, in the $\mathrm{MOG}_{35-55}$-induced EAE mouse model, an accumulating body of evidence also indicates a possible contribution of myelin-reactive antibodies to EAE pathogenesis [18]. First, the transfer of anti-MOG serum from $M_{30 G}$-55-immunized mice has been demonstrated to increase the severity of EAE in wild-type (WT) mice [19]; second, significant positive correlations were established between anti-MOG ${ }_{35-55}$ antibody levels and clinical scores, leukocyte infiltration and reactive astrocytosis in the spinal cord of an animal model of EAE achieved with a multiple $\mathrm{MOG}_{35-55}$ peptide [20]; and third, mice immunized with $\mathrm{MOG}_{35-55}$ peptides developed significant serum levels of anti-MOG antibodies coinciding with clinical EAE severity [21]. These studies imply that MOG peptidespecific antibodies may be pathogenic in this strain, as appears to be the case in several mouse and rat strains [22].

The capacity of anti-MOG antibodies to contribute to an ongoing CNS inflammatory and demyelinating response has been previously demonstrated in models of antibody-augmented EAE [23-26]. However, how such autoantibodies might mediate tissue destruction and demyelination in EAE remains a subject of intense debate [27]. Traditionally, pathogenic antibodies or autoantibodies have been implicated in MS through their ability to mediate their effector function, either via recruitment of the classical complement cascade or through activatory Fc receptor $(\mathrm{Fc} \gamma \mathrm{R})$-mediated antibody-directed cellmediated cytotoxicity (ADCC) [27]. The presence of deposited IgG around the borders of actively demyelinating MS plaques correlates with the presence of activated complement fragments and complexes [5,28,29] and antibodies bound to fragment of myelin within phagocytic cells are found at the sites of demyelination [30,31]. In EAE, the role of complement and Fc receptors in disease pathogenesis remains unclear. Although demyelination was found to be augmented in brains and spinal cords of transgenic mice engineered to produce increased levels of anti-MOG antibodies [26], experiments demonstrated that complement has little or no involvement in the autoantibody-mediated pathology, but that the mechanism for exacerbation involved Fcmediated effects [32]. However, other data indicate that inoculation of anti-MOG antibodies drastically increases clinical $\mathrm{MOG}_{35-55}$-induced EAE in an activatory $\mathrm{Fc} \gamma \mathrm{R}$ independent yet complement-dependent fashion [33], and that in the Lewis rats, the demyelination potential of MOG-specific antibodies has been shown to correlate with complement-binding ability [34]. The role of complement activation in $\mathrm{MOG}_{35-55}$-induced EAE has been debated. While complement-deficient mice $[35,36]$ or expression of the complement inhibitor sCrry attenuates EAE [37], other data indicate that key components of the complement system, such as $\mathrm{C} 1 \mathrm{q}, \mathrm{C} 3, \mathrm{C} 4$, and $\mathrm{C} 5 \mathrm{a}$, may not be involved in $\mathrm{MOG}_{35-55}$-induced EAE pathogenesis $[33,36,38,39]$.

Regarding the role of autoantibodies in various autoimmune conditions, novel therapeutic agents that directly target pathogenic antibodies have recently been successfully developed. The IgG-degrading enzyme of Streptococcus pyogenes (IdeS) prevented an antibody-induced relapse in mice that had chronic arthritis, and delayed the onset and reduced the severity of experimental collageninduced arthritis (CIA) [40]. Like IdeS, EndoS from Streptococcus pyogenes is an immunomodulating enzyme that specifically hydrolyzes glycans from human IgG, and thereby affects antibody effector functions. EndoS has recently been demonstrated as an attractive treatment in autoantibody-mediated autoimmune disease mouse models of CIA [41], lethal IgG-driven immune thrombocytopenic purpura (ITP), autoimmune hemolysis [42,43], and glomerulonephritis [44]. Thus, modulation of IgG glycosylation is a promising strategy to interfere with autoantibody-mediated inflammatory processes, such as those that may take place during the pathogenesis of MS or its animal model, EAE.

In the present study, we evaluated the importance of glycosylation of the IgG molecule by EndoS treatment in MOG $_{35-55}$-induced EAE, the most commonly used model to study the efficacy of potential drugs for the treatment of MS. In this chronic demyelinating disease of the CNS we previously showed that specific antibodies against MOG and nucleic acids (RNA and ssDNA) paralleled disease progression. Here, we observed that IgG deglycosylation by EndoS treatment attenuates $\mathrm{MOG}_{35-55}$-induced EAE development in WT mice but not in B-cell-deficient mice, suggesting that antibodies aggravate the clinical course in this EAE model. Histological analysis showed reduced CNS inflammatory lesions and demyelination. Data also revealed significantly reduced serum complement consumption and CNS deposition in EndoS-treated mice versus untreated mice, suggesting a key role for complement in EAE progression. Collectively, this study establishes a role for antibodies in MOG peptide-induced immune-mediated demyelination, a model largely considered to be purely $\mathrm{T}$ cell-dependent, and suggests that complement activation may be relevant in the context of antibody-exacerbated EAE. 


\section{Materials and methods Ethics statement}

Animal experiments described in the present study were approved by the Ethics Committee for Animal Experimentation of the Faculty of Medicine, University of Geneva, Switzerland (protocol ID number: 1005/3537/3).

\section{Induction of EAE}

Acute chronic EAE was induced in 6- to 8-week-old WT or B cell-deficient ( $\mu$ MT KO) C57BL6J female mice, as previously reported $[45,46]$. Briefly, mice were immunized subcutaneously with $100 \mu \mathrm{g}$ of $\mathrm{MOG}_{35-55}$ peptide (MEVGWYRSPFSRVVHLYRNGK; AnaSpec, USA) emulsified in CFA and supplemented with $200 \mu \mathrm{g}$ of Mycobacterium tuberculosis strain H37RA (Difco, Detroit, MI, USA). The mice received intravenous injections with $300 \mathrm{ng}$ pertussis toxin (Sigma-Aldrich, St Louis, MO, USA) at the time of immunization and $48 \mathrm{~h}$ later. Clinical disease was scored daily as follows: 0, no clinical disease; 1 , limp tail; 2, impaired righting reflex; 3 , hind limb paralysis; 4, moribund; 5, dead. Severely paralyzed mice were afforded easier access to food and water. Each time point presents the average disease score of each group. Statistical significance was assessed using an unpaired Student's $t$-test.

\section{EndoS enzyme treatment}

EndoS was recombinantly expressed in E. coli and purified as previously described [47]. EndoS treatment (intravenous, $20 \mu \mathrm{g}$ ) was initiated 1 day before disease induction, before disease onset (day 7), and during the acute phase of the disease (day 14). Control animals received placebo (PBS) injections.

\section{Analysis of IgG glycan hydrolysis}

Mice were bled (tail) on day 1 before immunization, and on days 7 and 14 after immunization. Serum was isolated after coagulation and centrifugation $(15 \mathrm{~min}$ at $3000 \mathrm{~g}$ ) and kept frozen at $-20^{\circ} \mathrm{C}$ until use. Purification of total IgG in plasma was performed using protein G Sepharose according to the manufacturer's instructions (GE Healthcare Biosciences). Purified IgG was separated using 10\% SDS-PAGE and stained with Coomassie blue (total protein stain), or electroblotted onto polyvinylidene difluoride (PVDF) membranes (immobilon-P; Millipore, Bedford, MA, USA). Equal amounts of material were loaded into each well during SDS-Page analysis. Glycosylated IgG was detected using $1 \mu \mathrm{g} / \mathrm{mL}$ biotinylated Lens culinaris agglutinin-A (LCA) lectin and $1 \mu \mathrm{g} / \mathrm{mL}$ of streptavidinhorseradish peroxidase (Vector Laboratories, Burlingame, CA, USA) and SuperSignal West Pico peroxidase substrate (Pierce, Rockford, IL, USA). Membranes were analyzed using a Chemidoc XRS imaging system and
Quantity One image analysis software (Bio-Rad, Hercules, CA, USA).

\section{Serological assay}

Serum levels of total IgG were determined by ELISA as described previously [21]. IgG results are expressed in $\mu \mathrm{g} / \mathrm{mL}$ by referring to a standard curve obtained using a mouse serum with known IgG concentrations (Miles Laboratories).

\section{Isolation of CNS-infiltrating mononuclear cells}

Mice were anesthetized with sodium thiopental and perfused through the left ventricle with cold PBS until the effluent ran clear. Spinal cords were extruded by flushing the vertebral canal with cold PBS, rinsed in PBS, and minced with a scalpel blade. The spinal cords were forced through 100-mesh stainless steel screens (Falcon, BD Biosciences) to obtain a single-cell suspension in HBSS containing $300 \mathrm{U} / \mathrm{mL}$ per cord of type IV clostridial collagenase (Sigma), and were then incubated for $1 \mathrm{~h}\left(37^{\circ} \mathrm{C}\right)$. The spinal cord homogenate was resuspended in 30\% Percoll (Sigma) and underlaid with $70 \%$ Percoll. The gradients were centrifuged at $500 \mathrm{~g}$ at $24^{\circ} \mathrm{C}$ for $20 \mathrm{~min}$. CNS mononuclear cells were collected from the $30 \% / 70 \%$ interface and were washed and resuspended in RPMI 1640 medium (Invitrogen) supplemented with $2 \mathrm{mM}$ L-glutamine, $25 \mathrm{mM}$ HEPES, $100 \mathrm{U} / \mathrm{mL}$ penicillin, $100 \mu \mathrm{g} / \mathrm{mL}$ streptomycin, 2-mercaptoethanol (2-ME), and $10 \%$ fetal calf serum (FCS) (all supplements from Invitrogen). Typical recovery yielded from $5 \times 10^{5}$ to $1 \times 10^{6}$ cells per spinal cord.

\section{Isolation of bone marrow cells}

Bone marrow cell suspensions were isolated by flushing the femurs and tibias harvested from EndoS- and PBStreated mice at peak disease. Bone marrow cells were resuspended in complete RPMI 1640 medium (Invitrogen) supplemented with $2 \mathrm{mM}$ L-glutamine, $25 \mathrm{mM}$ HEPES, $100 \mathrm{U} / \mathrm{mL}$ penicillin, $100 \mu \mathrm{g} / \mathrm{mL}$ streptomycin, 2-ME, and 10\% FCS (all supplements from Invitrogen).

\section{Spleen cell proliferation assay}

Splenocyte cell suspensions were isolated from $\mathrm{MOG}_{35-55^{-}}$ immunized mice at day 22 by homogenizing spleens through a cell strainer $\left(70 \mu \mathrm{m}\right.$ Nylon, Falcon $\left.{ }^{\circledR}\right)$ and removing red blood cells with ACK lysing buffer (BioWhittaker, Walkersville, MD, USA). Splenocytes from six separate mice from the same group were plated in triplicate in 96-well round bottom plates at $2 \times 10^{5}$ cells/well in $200 \mu \mathrm{L}$ complete RPMI 1640 medium (Invitrogen) supplemented with $2 \mathrm{mM}$ L-glutamine, $25 \mathrm{mM}$ HEPES, $100 \mathrm{U} / \mathrm{mL}$ penicillin, $100 \mu \mathrm{g} / \mathrm{mL}$ streptomycin, 2-ME, and 10\% FCS (all supplements from Invitrogen) containing either 0 to $50 \mu \mathrm{g} / \mathrm{mL}$ of $\mathrm{MOG}_{35-55}$ or $\mathrm{CpG}$ 
$(2 \mu \mathrm{g} / \mathrm{mL})$ and cultured at $37^{\circ} \mathrm{C}, 5 \% \mathrm{CO}_{2}$ for $72 \mathrm{~h}$. Proliferation was measured by incorporation of ${ }^{3} \mathrm{H}$ methylthymidine $(1 \mu \mathrm{Ci} /$ well $)$ during the last $16 \mathrm{~h}$ of culture using a filtermate harvester (Packard Instrument Co.) and a 1450 microbeta liquid scintillation counter (PerkinElmer). Results were determined as mean \pm SD from triplicate cultures.

\section{Immunologic markers and flow cytometry}

Cells from spleens, bone marrow, and spinal cords were incubated for $30 \mathrm{~min}$ at $4^{\circ} \mathrm{C}$ with FITC, PE, PerCP-Cy5, or APC fluorochromes conjugated with: CD4, CD8, CD11c, CD11b, CD138, B220, CD69, and CD44. To block non-specific Fc-mediated interactions, cells were incubated in blocking solution (PBS with 1\% FCS) for $20 \mathrm{~min}$ on ice prior to staining. Samples were run through a FACS Calibur flow cytometer (Becton Dickinson) with standard equipment. Flow cytometry acquisitions were analyzed using FlowJo analysis software (Version 9.3.2).

\section{Histopathology and immunostaining}

Spinal cords at peak of disease (day 22) obtained from transcardially perfused mice (4\% paraformaldehyde) were embedded in paraffin ( $n=4$ to 6 animals per experimental group). Paraffin-embedded blocks were cut into $5-\mu \mathrm{m}$ thick sections and stained with hematoxylin-eosin (HE) to assess inflammation or luxol fast blue/periodic acid Shiff stain (LFB/PAS) to assess the degree of demyelination. Quantification was performed by examining five tranverse sections from the cervical to thoracic spinal cord per mouse, as described previously [48].

For immunohistochemistry, endogenous peroxidases (PBS/3\% hydrogen peroxide) were inactivated and unspecific binding was blocked (PBS/10\% FCS), followed by incubation with rabbit polyclonal anti-mouse C9 primary antibodies (provided by Dr M Collin, University of Sweden). Bound primary antibodies were visualized using an avidin-biotin technique with 3,3'-diaminobenzidine as chromogens (hemalaun counterstaining of nuclei). No significant staining was detected in slides incubated with control rabbit IgG. Numbers of C9-positive deposits within spinal cord lesions/spinal cord white matter (over an area of at least $150 \mu \mathrm{m} \times 150 \mu \mathrm{m}$ per animal) were expressed as C9 density per $\mu \mathrm{m}^{2}$ (density index). Rabbit polyclonal anti-mouse $C 9$ primary antibodies were used to perform the immunofluorescent double staining. The distribution of the primary antibodies was visualized using anti-rabbit IgG secondary antibody conjugated to the rhodamine fluorochrome. DAPI stain was applied to visualize cell nuclei. For negative controls, the primary antibody was replaced with the appropriate non-immune serum. To control for cross-reactivity in double immunofluorescence, sections were incubated with secondary antibody only.

\section{Western blotting}

Spinal cords from EndoS-treated mice and control PBStreated C57BL6J mice were homogenized using a polytron in lysis buffer (50 mM Tris-HCl, pH 7.5, $250 \mathrm{mM}$ $\mathrm{NaCl}, 1 \%$ Triton X-100, 1 mM EDTA, 1 mM DTT) containing complete protease inhibitors (Roche) and incubated $30 \mathrm{~min}$ on ice. Lysates were sonicated and clarified by centrifugation. Protein concentration of the different lysates was determined using Bradford analyses. Aliquots containing equal amounts $(20 \mu \mathrm{g})$ of total protein or serum were heated to $90^{\circ} \mathrm{C}$ for $5 \mathrm{~min}$ in SDS-sample buffer containing 5\% 2-ME (Sigma, Chicago, IL, USA), transferred to a 7.5-12.5\% SDS-polyacrylamide gel and blotted on an Immobilon-P PVDF membrane (Millipore, Bedford, MA, USA). After blotting of the proteins, the blocking and antibody incubation steps were performed in BPS containing 5\% non-fat milk and 0.1\% Tween 20 (Sigma). Complement C1q, C3 (in-house made by Dr S Izui, University of Geneva, Switzerland), and C9 (provided by $\mathrm{Dr}$ M Collin, Lund University, Sweden) were detected by incubating PVDF membranes $2 \mathrm{~h}$ at room temperature in buffer containing properly diluted goat anti-mouse anti-C1q and anti-C3 antibodies, and rabbit anti-mouse anti-C9 antibody. Binding of the primary antibody was detected using a peroxidase-conjugated secondary antibody to rabbit IgG (Jackson ImmunoResearch labs, West Grove, PA, USA). After washing, positive bands were visualized using chemiluminescence (Supersignal; Pierce, Rockford, IL, USA). Relative protein expression (mean of $n=3$ animals \pm s.e.m.) was quantified using Image J software (NIH).

\section{Statistical analysis}

Data are expressed as mean \pm s.e.m. and were analyzed by unpaired two-tailed Student's $t$-test, using Graphpad Prism 4.01 for Windows (Graphpad Software, San Diego, CA, USA). $P$ values $\leq 0.05$ were considered statistically significant.

\section{Results}

EndoS treatment ameliorates $\mathrm{MOG}_{35-55}$-induced EAE in wild-type (not B cell-deficient) mice

To evaluate the effect of IgG hydrolysis on $\mathrm{MOG}_{35-55^{-}}$ induced $\mathrm{EAE}$ in $\mathrm{C} 57 \mathrm{BL} / 6$ mice, we administered EndoS $(20 \mu \mathrm{g})(n=11)$ or PBS $(n=10)$ by subcutaneous injection to WT and B cell-deficient mice $(\mu \mathrm{MT}$ KO) 1 day prior to MOG-immunization, before disease onset (day 7), and during the acute disease phase (day 14) (Figure 1A). PBS-treated WT mice developed severe, chronic, progressive EAE, while disease severity was significantly diminished in WT mice treated with 

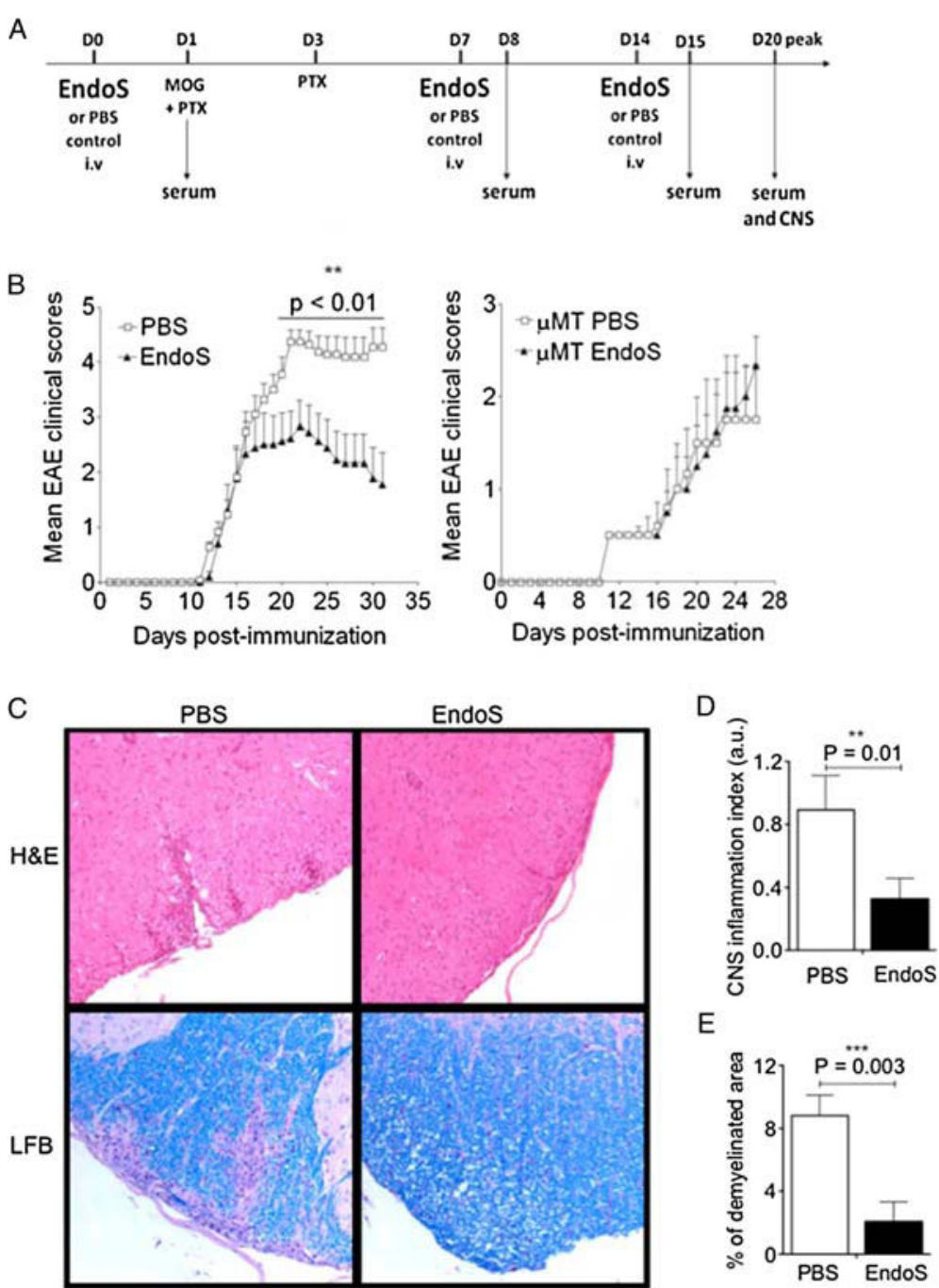

Figure 1 EndoS treatment ameliorates clinical and histological MOG $_{35-55}$-induced EAE. (A) A schematic representation of the experimental setup. (B) $M_{35}$-55-induced EAE is inhibited in WT mice, but not in B cell-deficient ( $\mu M T K O$ ) mice, treated with Endos; EAE scores were determined daily after disease onset in EndoS-treated mice (triangles; $n=11$ ) and PBS-treated controls (squares; $n=10$ ). Data are presented as mean EAE score \pm s.e.m. A significant statistical difference between the two groups of WT mice is observed from peak disease (day 20) to chronic phase (day 30). Data are representative of three individual experiments. $\left.{ }^{* *} P<0.01\right)$. (C) Representative images of paraffin-embedded spinal cord sections at peak disease (day 22) of indicated groups stained for hematoxylin and eosin (H\&E) or Luxol fast blue/Periodic acid Shiff stain (LFB/PAS) (magnification 200x) are shown. Five sections of spinal cord per mouse ( $n=6$ for EndoS-treated mice; $n=4$ for PBS-treated WT mice) were analyzed, and the number of (D) inflammatory lesions and (E) extent of demyelination per spinal cord section are presented as histograms. Error bars represent the mean \pm s.e.m. ${ }^{* *} P<0.01$ by Student's $t$-test.

EndoS (Figure 1B, left panel). In WT mice, EndoS treatment alleviated the severity of EAE during the acute phase (day 15 post-immunization) and impeded the full development of EAE during the chronic phase (from day 22 to 32 post-immunization) even though treatment was discontinued (Figure 1B). In contrast to WT mice, the positive treatment effect of EndoS in EAE was abrogated in $\mu \mathrm{MT} \mathrm{KO}$ mice, confirming that the beneficial effect of EndoS in $M_{35} \mathrm{G}_{35}$-induced EAE requires B cells or B cell products (Figure 1B, right panel).

\section{EndoS suppresses pathological signs of EAE}

Consistent with the clinical finding, histological examination of CNS tissues revealed a significant pathological difference between EndoS- and PBS-treated WT mice at the disease peak (Figure 1C). Figure 1D and $1 \mathrm{E}$ depict inflammation and demyelination scores from WT mice that received PBS or EndoS and were sacrificed on day 22 post-immunization. In PBS-treated WT mice, multiple inflammatory foci were observed in the white matter of the spinal cord, together with a high degree of demyelination. By contrast, significantly fewer inflammatory lesions and 
little demyelination were detected in EndoS-treated WT mice.

\section{Endoglycosidase treatment efficiently hydrolyzes IgG glycans in vivo in EAE mice}

To investigate the IgG glycan-hydrolyzing activity of EndoS in the circulation of live animals, C57BL6/J WT mice were intravenously injected three times (on days 0,7 , and 14) with PBS or $20 \mu \mathrm{g}$ of EndoS, and serum IgG samples (drawn on days $1,8,15$, and 25) were analyzed for glycosylation status using sodium dodecyl sulfate polyacrylamide gel electrophoresis (SDS-PAGE) and lectin blot analyses using Lens culinaris agglutinin-A (LCA blots). We first demonstrated that systemic EndoS treatment did not affect IgG antibody titers during the acute and chronic phases of EAE (Figure 2A). As previously reported [21], we observed that IgG levels tightly coincided with increased disease severity, reaching $6.56 \pm 0.5 \mathrm{mg} / \mathrm{mL}$ (mean \pm s.e.m.) at day 15 and $8.59 \pm 0.53 \mathrm{mg} / \mathrm{mL}$ at day 25 post-immunization, compared with $1.516 \pm 0.28 \mathrm{mg} / \mathrm{mL}$ before disease onset in PBS-treated mice $(P<0.0001$,

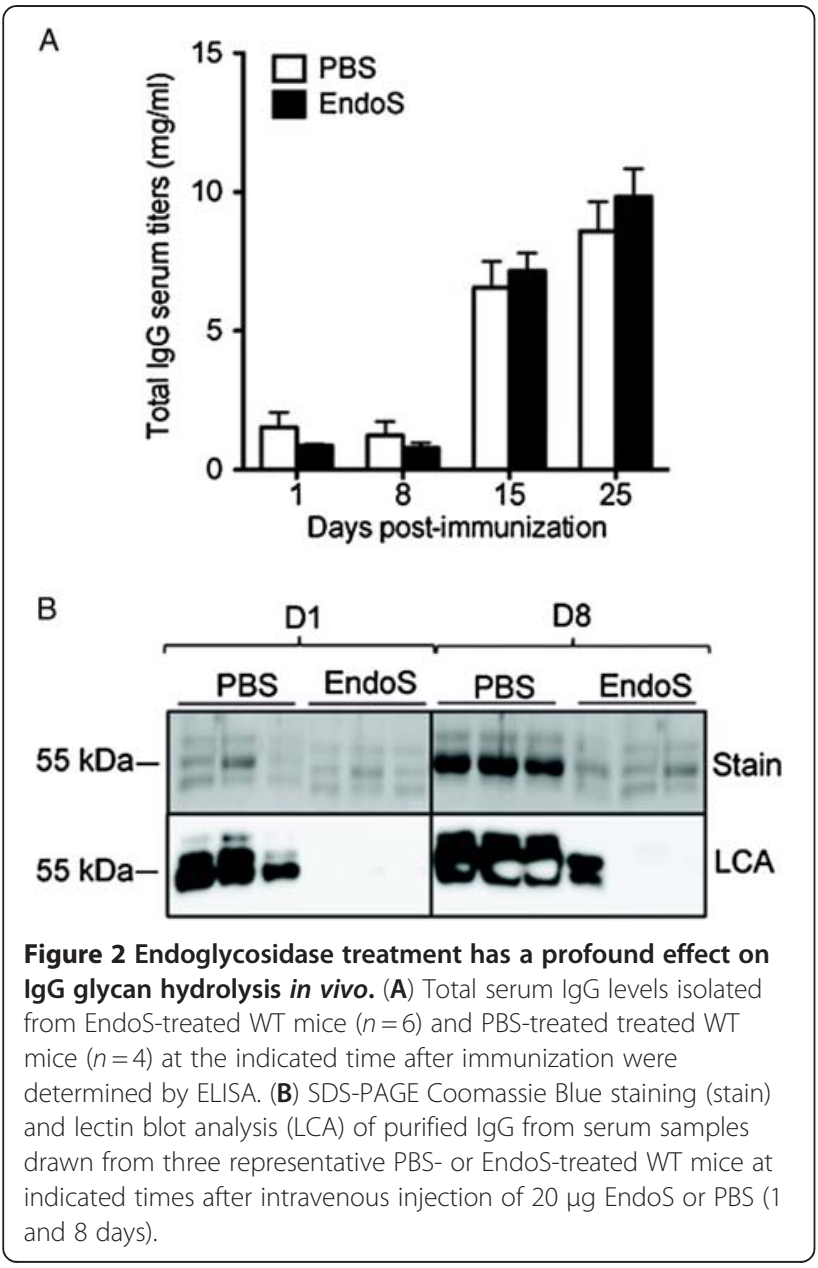

Student's $t$-test) (Figure 2A). One day after EndoS injection, the apparent molecular mass of the serum IgG heavy chain from EndoS-treated mice revealed a complete shift toward an approximate 3-kDa smaller protein band, compared with fully glycosylated intact mouse IgG from PBStreated mice (Figure 2B, stain blot). The apparent lack of correlation between serum IgG levels (Figure 2A) and the heavy chain signal (Figure 2B, stain blot) is likely to reflect the different sensitivities of the two assays. Lectin blot analysis revealed that the serum IgG heavy chain carbohydrate signal was abolished one day after EndoS injection, further confirming complete IgG glycan hydrolysis (Figure 2B, LCA blot). The IgG glycan hydrolysis patterns were nearly identical after injections 1 and 2, compared with mice that had not previously been exposed to EndoS (Figure 2B), with the exception of one animal that exhibited partial hydrolysis of IgG by EndoS on day 8 .

EndoS treatment does not influence peripheral or central immune cell function during EAE

Considering the fact that $\mathrm{CD} 4^{+} \mathrm{T}$ cells are initiators of EAE and drivers of neuro-immune degeneration in the CNS, we investigated whether EndoS treatment would interfere with their cellular functions. We observed that EndoS treatment did not block the T-cell recall response to the encephalitogenic peptide $\mathrm{MOG}_{35-55}$, suggesting that EndoS had no impact on peripheral priming of MOG-specific autoreactive $\mathrm{T}$ cells (Figure 3A). In support of this assumption, we observed no difference in $\mathrm{T}$ cell $\left(\mathrm{CD}^{+}\right.$and $\left.\mathrm{CD} 8^{+}\right)$peripheral frequency (Figure $3 \mathrm{~B}$ ) or recruitment to the CNS between PBS- and EndoS-treated EAE mice (Figure 3C). Likewise, CpG-dependent B cell proliferation (Figure 3D), peripheral frequency of $\mathrm{CD} 44^{+}$or $\mathrm{CD} 9^{+}$activated $\mathrm{B}$ cells (Figure $3 \mathrm{~B}$ ), and $\mathrm{B}$ cell recruitment into the CNS (Figure $3 \mathrm{C}$ ) were not affected by EndoS treatment. In addition, we did not observe any difference in the peripheral or CNS frequency of myeloid cells, such as macrophages $\left(\mathrm{CD} 11 \mathrm{~b}^{+}\right)$and dendritic cells $\left(\mathrm{CD} 11 \mathrm{c}^{+}\right)$, prominent constituents of neuroinflammatory infiltrates in the CNS during EAE that have the capacity to activate $\mathrm{T}$ cells (Figure 3B,C). Finally, EndoS treatment did not affect the frequency or activation status of immune cells in the bone marrow (Figure 3E).

\section{EndoS treatment impairs IgG-dependent complement activation and consumption during $\mathrm{MOG}_{35-55}$-induced EAE}

To determine whether the mechanism by which EndoS protection involves the modulation of complement activation, we studied changes in complement component (C1q, C3, and C9) consumption in EndoS-treated and untreated WT mice by SDS-PAGE analysis at different 

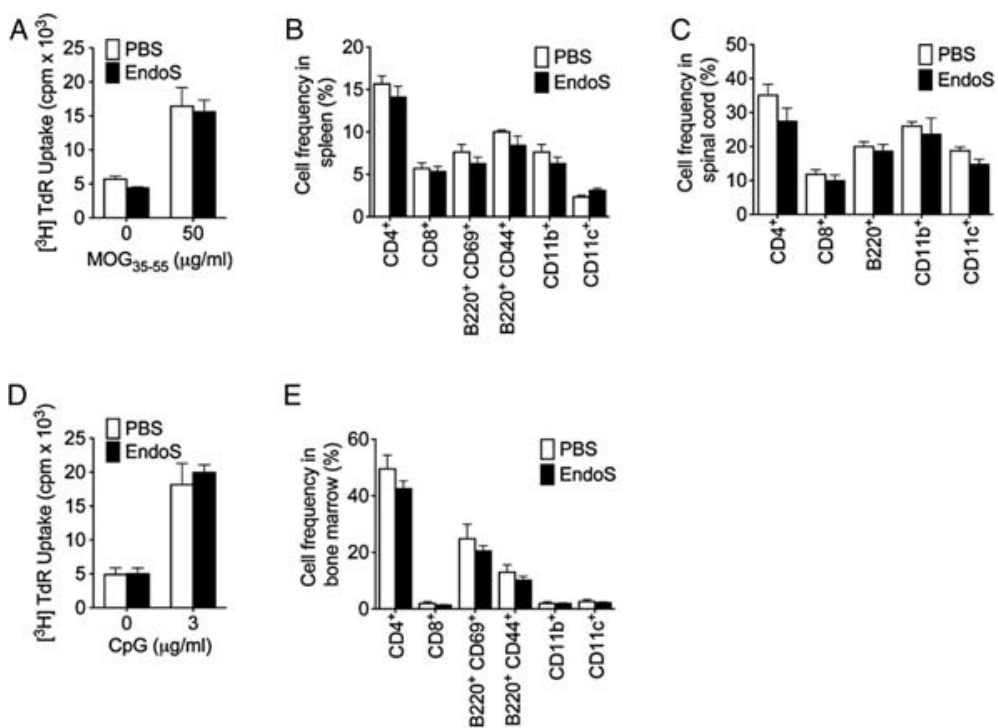

Figure 3 EndoS treatment does not limit T cell activation, B cell activation, or CNS recruitment of lymphoid or myeloid cells. (A) EndoS has no impact on peripheral T cell priming or recall responses of spleen cells in response to $\mathrm{MOG}_{35-55}$ peptide, as measured using a ${ }^{3} \mathrm{H}$ thymidine incorporation assay. EndoS treatment does not influence the (B) peripheral frequency or activation or (C) CNS (spinal cord) infiltration of important lymphoid and myeloid immune cell populations, as measured (mean \pm s.e.m.) by flow cytometry analysis of cells isolated from EndoS-treated mice $(n=6)$ and PBS-treated mice $(n=4)$ at day 25 post-immunization. (D) CpG is equally effective in stimulating the proliferation of splenic B cells from PBS- or EndoS-treated mice, as determined by ${ }^{3} \mathrm{H}$-thymidine incorporation after 3 days of culture. (E) EndoS treatment does not affect the frequency or activation status of immune cells in the bone marrow.

stages of the disease progression. As previously reported, EndoS hydrolysis of IgG glycan decreased serum complement activation as early as day 15 post-immunization in $\mathrm{MOG}_{35-55}$-induced EAE mice (Figure 4A,B). EndoS treatment had no effect on serum complement consumption at day 8 post-immunization, further confirming the absence of complement-activating IgG antibodies (Figure 2A) at the onset of EAE.

\section{Complement component deposition is reduced in the CNS by EndoS in EAE mice}

To investigate whether EndoS treatment influences CNS complement deposition during $\mathrm{MOG}_{35-55}$-induced $\mathrm{EAE}$, spinal cords from EndoS- and PBS-treated mice were examined at day 22 post-immunization (peak disease) for immunohistochemical detection of complement component C9. We observed a significant reduction of C9

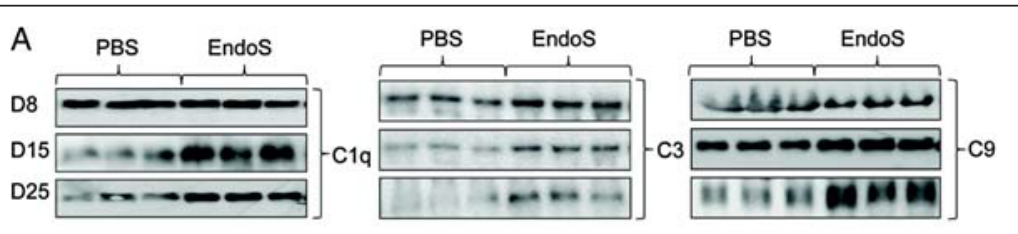

B
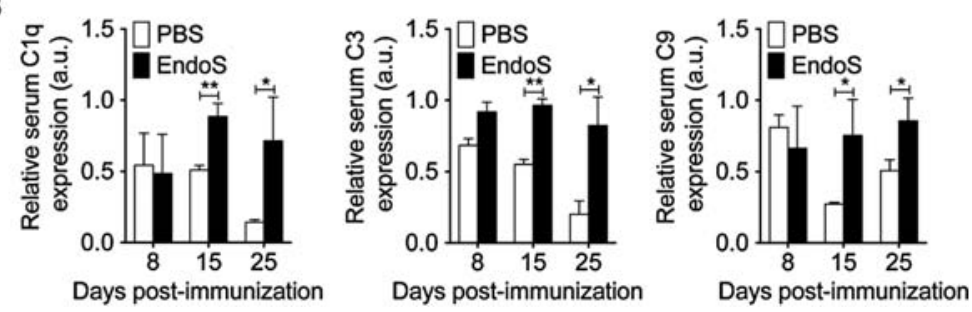

Figure 4 EndoS inhibits peripheral complement activation in EAE mice. (A) Serum complement activation or consumption of complement components C1q, C3, and C9 was evaluated by SDS-PAGE analysis of sera from EndoS- and PBS- treated WT mice ( $n=3$ per group) at the indicated time after immunization. (B) Relative serum expression of complement components C1q, C3, and C9 ( $n=3$ independent mice per group) was expressed as arbitrary units of density of bands (intensity/ $\mathrm{mm}^{2}$ ). 
deposit density in EndoS-treated mice $\left(0.58 \pm 0.06 \times 10^{3} /\right.$ $\mu \mathrm{m}^{2}, n=35$ lesions) compared with PBS-treated control mice $\left(2.05 \pm 0.16 \times 10^{3} / \mu \mathrm{m}^{2}, n=36\right.$ lesions) (Figure 5A,B). Consistent with this observation and peripheral $\mathrm{C} 9 \mathrm{com}$ plement activation, C9 was detected by western blotting and immunofluorescence microscopy in spinal cord from PBS-treated, but not EndoS-treated, WT mice (Figure 5C, D). These data suggest both a role for $\mathrm{C} 9$ in brain inflammation during $\mathrm{MOG}_{35-55}$-induced EAE, and a possible inhibitory mechanism of action of EndoS.

\section{Discussion}

EAE shares clinical and histopathological similarities with MS and serves as the most widely used animal model for the disease. Data from MS patients and EAE studies support a role for B cells/antibodies in the disease process. The presence of oligoclonal bands in the cerebrospinal fluid (CSF) of MS patients, and their

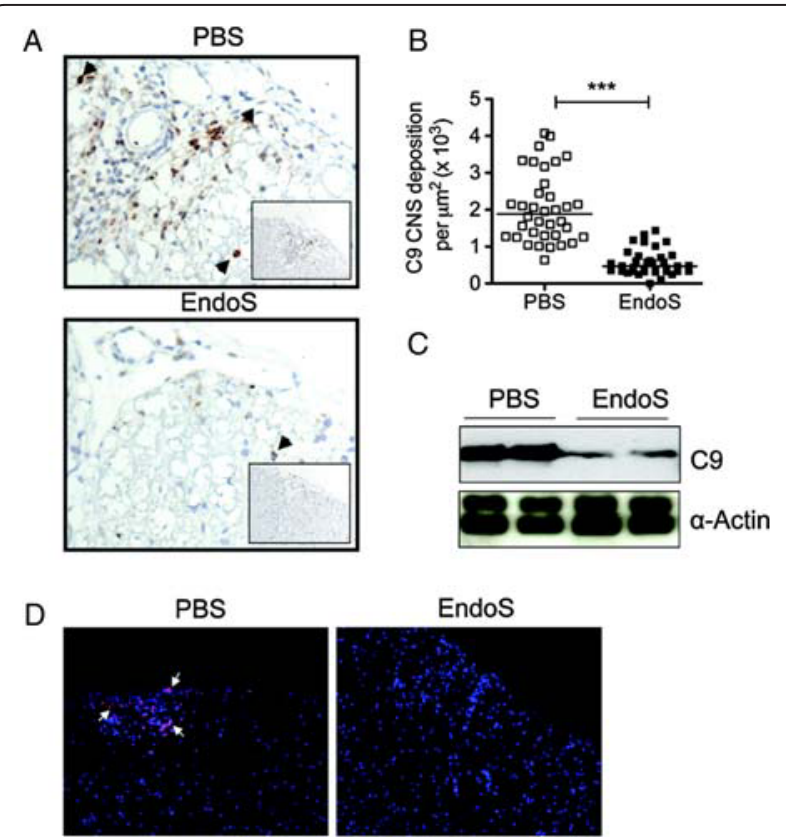

Figure 5 High levels of $\mathrm{C} 9$ are detected in the spinal cord of PBS-treated EAE mouse models, but absent from EAE mice treated with EndoS. (A) Representative C9 immunostaining (brown) in the spinal cord of WT MOG 35 -55 peptide-induced EAE mice at day 22 post-immunization (disease peak) (magnification 200x). (B) EndoS treatment significantly lowered the density of C9 deposits in mouse spinal cord $(n=4)$. ${ }^{* *}, P \leq 0.001$ by Student's $t$-test. (C) A representative western blot of spinal cord extracts from EndoS- and PBS-treated mice ( $n=3$ per group) probed with the anti-C9 antibody. Anti-a-Actin served as the loading control. (D) Complement C9 deposition in the CNS is strongly reduced by EndoS treatment in EAE mice. Double-label immunofluorescence microscopy demonstrated that complement component C9 (pink-purple) is deposited in the CNS of PBS-treated (but not EndoS-treated) mice. Cell nuclei were counterstained with DAPI (blue). association with a worse prognosis, supports a pathogenic role for antibodies in CNS autoimmunity [49,50]. Here, we established that enzymatic IgG glycan hydrolysis by EndoS attenuates $\mathrm{MOG}_{35-55}$-induced EAE. We observed no differences in CNS-infiltrating $\mathrm{CD} 4^{+} \mathrm{T}$ cell frequencies or activation during EAE, confirming that EAE protection occurs independently of $T$ cell immunity. Clinical benefit of EndoS treatment in mice was associated with reduced complement system activation in the presence of comparable IgG levels between treated and untreated groups, supporting a profound effect of IgG glycan on IgG effector functions. Overall, our data strengthen the importance of antibodies in $\mathrm{MOG}_{35-55}$-induced EAE, a model of CNS inflammation that is considered less dependent upon B cells and humoral immune responses, and also suggest that the EndoS enzyme could be used as an immunomodulatory therapeutic agent against IgG-mediated CNS autoimmune diseases.

Although the role of $\mathrm{CD} 4^{+} \mathrm{T}$ cells in EAE/MS initiation is widely accepted, the role of $\mathrm{B}$ cells and antibodies in disease pathogenesis remains unclear. Several previous studies have however provided cumulative evidence for an active role of anti-myelin antibodies in inducing demyelination $[7,8,11]$. In EAE, although anti-MOG antibodies cannot trigger CNS inflammation on their own, they strongly augment $\mathrm{T}$ cell-initiated and macrophageenhanced demyelination, and may augment disease severity $[51,52]$. Several studies indicate that the demyelinating activity of myelin-specific antibodies is related to their ability to fix complement [53]. Other roles for B cells in MS/EAE pathogenesis include directing the polarization, activation, or specificity of disease-relevant $T$ cells $[13,54]$, production of pro- and anti-inflammatory cytokines, and potentiation of remyelination [55].

Early studies in the C57BL/6 mouse EAE model have indicated that the induction of disease may be $\mathrm{B}$ celldependent, depending on the source and nature of the MOG immunogen. Induction of EAE after immunization with $\mathrm{MOG}_{35-55}[17,25]$ or recombinant MOG (rMOG) protein from mouse or rat $[17,56]$ but not human $[25,56]$ was shown to be B cell-independent. However, recent B cell depletion studies and other experimental paradigms have demonstrated both protective and pathogenic roles for B cells in EAE models in which they were previously considered to contribute only marginally to disease pathogenesis [13,14,17]. Previous data from the EAE models indicated that the role of antibodies in the disease process might differ based on the model employed [25,56]. While immunization with rodent or human rMOG [56] or $\mathrm{MOG}_{35-55}$ [57] leads to the development of antibodies that bind mouse MOG, reports indicate that only MOG-specific antibodies generated in response to human rMOG are pathogenic [25]. However, recent 
cumulative data support a pathogenic role for antibodies in $\mathrm{MOG}_{35-55}$-induced EAE in C57BL/6 mice [18-21].

In this study, we report that specific IgG glycan hydrolysis by EndoS attenuates $\mathrm{MOG}_{35-55}$-induced EAE independent of $\mathrm{T}$ cell immunity. Importantly, we observed a clear association between the appearance of serum antibodies and the occurrence of clinical EAE signs. In this context, we found that the beneficial effect of EndoS in neutralizing the effector functions of antibodies was only evident shortly after disease onset, when myelinspecific antibodies are thought to contribute to disease progression. Additionally, our findings demonstrating a reduction of complement activation, and in particular C9, after EndoS administration are strongly suggestive of a role for this system in the development and clinical expression of $M_{35}$-55-induced EAE. In addition to the complement system, it is also conceivable that EndoS might interfere with a function of FcR in antibodymediated demyelination [58,59], such as inefficient ADCC [60]. However, this concept is strongly challenged by EAE studies indicating that autoantibody-directed demyelination depends on complement activation but not activatory $\mathrm{Fc} \gamma \mathrm{R}[33,59]$ and that the antibody-binding FcaR units are not required for disease development [61].

Several reports indicate that complement activation may play an essential role in the mediation and maintenance of inflammatory reactions and the process of demyelination in the CNS [62], particularly in diseases such as MS and neuromyelitis optica (NMO). Terminal complement component has been shown in actively demyelinating areas of the CNS in MS [5,63], and evidence exists that complement (specifically, the assembly of the C5b-9 complex) promotes myelin damage and demyelination in well myelinated mouse cerebellum cultures [64]. Increased levels of the C5b-9 complex have been detected in the spinal fluid of MS patients during relapses [65,66], and these levels have been correlated with neurological disability. In EAE, several studies have used experimental manipulations that reduce the activation of the complement to evaluate its role in disease pathogenesis. Among others, serum complement depletion with cobra venom factor (CVF) reduced actively induced acute EAE in rats [62]. Similar to our findings, CVF and its effect on the complement cascade have been shown to reduce the severity of EAE-related inflammation and demyelination without significantly influencing certain histopathological concomitants $[23,62]$. In support of our findings, activation of C9 (the major component of the cytolytic membrane attack complex) in EAE is related to myelin injury rather than CNS inflammation [67].

While our data indicate that reduced complement activation by EndoS hydrolysis of IgG may account for its clinical benefit in EAE, recent findings suggest that EndoShydrolyzed human IgG does bind better to FcyRIIb than non-hydrolyzed IgG under certain circumstances [68]. In the context of $\mathrm{MOG}_{35-55}$-induced EAE pathogenesis, this finding might be relevant, as recent evidence suggest that autoimmune-prone FcyRIIb-deficient mice exhibit more pronounced $\mathrm{MOG}_{35-55}$-induced EAE disease [60]. Importantly, intravenous Ig (IVIG) injection, which is reportedly therapeutic in $\mathrm{MOG}_{35-55}$-induced EAE [69] and has exhibited some evidence of efficacy in MS [70], may act by targeting the low-affinity IgG inhibitory receptor FcyRIIb [71]. Therefore, one could speculate that EndoS treatment in $\mathrm{MOG}_{35-55}$-EAE may have a dual antiinflammatory activity, both inhibiting the activation of the complement and shifting the binding of pathogenic IgG toward the inhibitory action mediated through Fc $\gamma$ RIIb. Although additional studies are needed to test this hypothesis, it represents a potential additional mechanism of action of EndoS that could account for its protective effects in EAE. Moreover, while data indicate that EndoS specifically hydrolyzes native IgG (no other substrate has been identified to date) [47], we could not exclude the possibility that EndoS could cleave glycans other than those on IgG. Whether IgG deglycosylation plays a more significant role in a B cell-dependent EAE model using recombinant MOG protein would therefore be of specific interest.

The presence of Ig's and complement activation products in active MS lesions and the efficacy of therapeutic plasma exchange in some patients provide circumstantial evidence for the involvement of antibodies in MS $[72,73]$. Here, we establish that administration of EndoS, an enzyme from Streptococcus pyogenes that efficiently hydrolyzes the functionally important and conserved $\mathrm{N}$ linked glycan of IgG in vivo, significantly attenuates disease progression in a model of CNS inflammation and demyelination. Together with treatment with B celldepleting antibodies that target cellular function of $\mathrm{B}$ cells [74], we propose that EndoS-mediated IgG hydrolysis may constitute a potential novel therapeutic principle for the treatment of IgG-driven human CNS autoimmune diseases such as MS. Reasonable pharmacokinetics of this enzyme is further ensured by its ability to avoid antibodymediated elimination [42] via removal of glycans necessary for the binding of neutralizing antibodies.

\section{Competing interests}

Patents for the in vitro and in vivo use of Endos have been applied for by Genovis $A B$ and Hansa Medical $A B$, respectively. $M C$ is listed as an inventor on these applications that are pending. $M C$ is a part time scientific consultant for Hansa Medical AB.

Authors' contributions

$M B, N M, M-L S-R$, and PHL designed research; MB, NM, MC, and DM performed research; MC, M-LS-R, and MSW contributed new reagents or analytic tools; MB, NM, M-LS-R, and PHL analyzed data; MB, NM, and PHL wrote the paper. All authors read and approved the final manuscript. 


\section{Acknowledgments}

This work was supported by Grants \#310030-132705 (to P.H.L.) from the Swiss National Science Foundation, grants from the Swiss Society for Multiple Sclerosis (to NM and PHL), and by grants from the Swedish Research Council (MC), Alfred Österlund's Foundation (MC), Crafoord Foundation (MC), Greta and Johan Kock's Foundation (MC), King Gustaf V's 80th Birthday Foundation (MC), Hedlund's Foundation (MC), Swedish Rheumatism Association (MC), Swedish Society for Medicine (MC), Torsten and Ragnar Söderberg's Foundations (MC), Royal Physiografic Society (MC), Åke Wiberg's Foundation (MC) and Hansa Medical AB (MC). The funding bodies had no part in the study design, the collection, analysis and interpretation of the data, writing of the manuscript or the submission. NM is a recipient of an advanced researcher exchange 2011 fellowship from the European Committee for Treatment and Research in Multiple Sclerosis (ECTRIMS) Foundation. DM is supported by grants \# PP00P3_128372 from the Swiss National Science Foundation (Grant) and grants from the Swiss Society for Multiple Sclerosis.

\section{Author details}

'Department of Pathology and Immunology, Faculty of Medicine, University of Geneva, 1211, Geneva, Switzerland. 'Department of Clinical Neurosciences, Division of Neurology, Unit of Neuroimmunology and Multiple Sclerosis, Geneva University Hospital, 1211 Geneva, Switzerland. ${ }^{3}$ Department of Neurology, Technische Universität München, D-08538 Munich, Germany. ${ }^{4}$ Division of Clinical Pathology, Geneva University Hospital, 1211 Geneva, Switzerland. ${ }^{5}$ Department of Neuropathology, University Medical Center, Georg August University, Göttingen, Germany. 'Department of Clinical Sciences, Division of infection Medicine, Lund University, SE-221 84 Lund, Sweden. ${ }^{7}$ Department of Genetic and Laboratory Medicine, Division of Laboratory Medicine, Geneva University Hospital, 1211 Geneva, Switzerland.

Received: 22 June 2012 Accepted: 14 August 2012

Published: 3 September 2012

\section{References}

1. von Budingen HC, Bar-Or A, Zamvil SS: B cells in multiple sclerosis: connecting the dots. Curr Opin Immunol 2011, 23:713-720.

2. Blennow K, Fredman P, Wallin A, Gottfries CG, Frey H, Pirttila T, Skoog I, Wikkelso C, Svennerholm L: Formulas for the quantitation of intrathecal IgG production. Their validity in the presence of blood-brain barrier damage and their utility in multiple sclerosis. J Neurol Sci 1994, 121:90-96.

3. Meinl E, Krumbholz M, Hohlfeld R: B lineage cells in the inflammatory central nervous system environment: migration, maintenance, local antibody production, and therapeutic modulation. Ann Neurol 2006, 59:880-892.

4. Serafini B, Rosicarelli B, Magliozzi R, Stigliano E, Aloisi F: Detection of ectopic B-cell follicles with germinal centers in the meninges of patients with secondary progressive multiple sclerosis. Brain Pathol 2004, 14:164-174.

5. Storch MK, Piddlesden $\mathrm{S}$, Haltia M, livanainen $M$, Morgan $\mathrm{P}$, Lassmann $\mathrm{H}$ : Multiple sclerosis: in situ evidence for antibody- and complementmediated demyelination. Ann Neurol 1998, 43:465-471.

6. Breij EC, Brink BP, Veerhuis $R$, van den Berg C, Vloet $R$, Yan R, Dijkstra CD, van der Valk P, Bo L: Homogeneity of active demyelinating lesions in established multiple sclerosis. Ann Neurol 2008, 63:16-25.

7. Lalive PH, Menge T, Delarasse C, Della Gaspera B, Pham-Dinh D, Villoslada P, von Budingen $\mathrm{HC}$, Genain CP: Antibodies to native myelin oligodendrocyte glycoprotein are serologic markers of early inflammation in multiple sclerosis. Proc Natl Acad Sci U S A 2006, 103:2280-2285.

8. Menge T, von Budingen HC, Lalive PH, Genain CP: Relevant antibody subsets against MOG recognize conformational epitopes exclusively exposed in solid-phase ELISA. Eur J Immunol 2007, 37:3229-3239.

9. Menge T, Lalive PH, von Budingen HC, Genain CP: Conformational epitopes of myelin oligodendrocyte glycoprotein are targets of potentially pathogenic antibody responses in multiple sclerosis. J Neuroinflammation 2011, 8:161.

10. Lalive PH, Hausler MG, Maurey H, Mikaeloff $Y$, Tardieu M, Wiendl $H$ Schroeter M, Hartung HP, Kieseier BC, Menge T: Highly reactive anti-myelin oligodendrocyte glycoprotein antibodies differentiate demyelinating diseases from viral encephalitis in children. Mult Scler 2011, 17:297-302.
11. Lalive PH: Autoantibodies in inflammatory demyelinating diseases of the central nervous system. Swiss Med Wkly 2008, 138:692-707.

12. Franciotta D, Salvetti M, Lolli F, Serafini B, Aloisi F: B cells and multiple sclerosis. Lancet Neurol 2008, 7:852-858.

13. Weber MS, Prod'homme T, Patarroyo JC, Molnarfi N, Karnezis T, Lehmann-Horn K, Danilenko DM, Eastham-Anderson J, Slavin AJ, Linington C, Bernard CC, Martin F, Zamvil SS: B-cell activation influences T-cell polarization and outcome of anti-CD20 B-cell depletion in central nervous system autoimmunity. Ann Neurol 2010, 68:369-383.

14. Matsushita T, Yanaba K, Bouaziz JD, Fujimoto M, Tedder TF: Regulatory B cells inhibit EAE initiation in mice while other $B$ cells promote disease progression. J Clin Invest 2008, 118:3420-3430.

15. Ray A, Basu S, Williams CB, Salzman NH, Dittel BN: A Novel IL-10-Independent Regulatory Role for B Cells in Suppressing Autoimmunity by Maintenance of Regulatory T Cells via GITR Ligand. J Immunol 2012, 188:3188-3198.

16. Barr TA, Shen P, Brown S, Lampropoulou V, Roch T, Lawrie S, Fan B, O'Connor RA, Anderton SM, Bar-Or A, Fillatreau S, Gray D: B cell depletion therapy ameliorates autoimmune disease through ablation of IL-6-producing B cells. J Exp Med 2012, 209:1001-1010.

17. Fillatreau S, Sweenie CH, McGeachy MJ, Gray D, Anderton SM: B cells regulate autoimmunity by provision of IL-10. Nat Immunol 2002, 3:944-950

18. Zhang GX, Yu S, Gran B, Li J, Calida D, Ventura E, Chen X, Rostami A: T cell and antibody responses in remitting-relapsing experimental autoimmune encephalomyelitis in (C57BL/6 x SJL) F1 mice. J Neuroimmunol 2004, 148:1-10.

19. Du C, Sriram S: Increased severity of experimental allergic encephalomyelitis in lyn-/- mice in the absence of elevated proinflammatory cytokine response in the central nervous system. J Immunol 2002, 168:3105-3112.

20. Costa O, Divoux D, Ischenko A, Tron F, Fontaine M: Optimization of an animal model of experimental autoimmune encephalomyelitis achieved with a multiple MOG(35-55)peptide in C57BL6/J strain of mice. J Autoimmun 2003, 20:51-61.

21. Lalive PH, Molnarfi N, Benkhoucha M, Weber MS, Santiago-Raber ML: Antibody response in MOG(35-55) induced EAE. J Neuroimmunol 2011, 240-241:28-33.

22. Bernard CC, Johns TG, Slavin A, Ichikawa M, Ewing C, Liu J, Bettadapura J: Myelin oligodendrocyte glycoprotein: a novel candidate autoantigen in multiple sclerosis. J Mol Med 1997, 75:77-88.

23. Piddlesden S, Lassmann H, Laffafian I, Morgan BP, Linington C Antibody-mediated demyelination in experimental allergic encephalomyelitis is independent of complement membrane attack complex formation. Clin Exp Immunol 1991, 83:245-250.

24. Schluesener HJ, Sobel RA, Linington C, Weiner HL: A monoclonal antibody against a myelin oligodendrocyte glycoprotein induces relapses and demyelination in central nervous system autoimmune disease. J Immunol 1987, 139:4016-4021.

25. Lyons JA, Ramsbottom MJ, Cross AH: Critical role of antigen-specific antibody in experimental autoimmune encephalomyelitis induced by recombinant myelin oligodendrocyte glycoprotein. Eur J Immunol 2002, 32:1905-1913.

26. Litzenburger T, Fassler R, Bauer J, Lassmann H, Linington C, Wekerle H, Iglesias A: B lymphocytes producing demyelinating autoantibodies: development and function in gene-targeted transgenic mice. J Exp Med 1998, 188:169-180.

27. Ravetch JV, Clynes RA: Divergent roles for Fc receptors and complement in vivo. Annu Rev Immunol 1998, 16:421-432.

28. Woyciechowska JL, Brzosko WJ: Immunofluorescence study of brain plaques from two patients with multiple sclerosis. Neurology 1977, 27:620-622.

29. Lucchinetti C, Bruck W, Parisi J, Scheithauer B, Rodriguez M, Lassmann H: Heterogeneity of multiple sclerosis lesions: implications for the pathogenesis of demyelination. Ann Neurol 2000, 47:707-717.

30. Genain CP, Cannella B, Hauser SL, Raine CS: Identification of autoantibodies associated with myelin damage in multiple sclerosis. Nat Med 1999, 5:170-175.

31. Raine CS, Cannella B, Hauser SL, Genain CP: Demyelination in primate autoimmune encephalomyelitis and acute multiple sclerosis lesions: a 
case for antigen-specific antibody mediation. Ann Neurol 1999, 46:144-160.

32. Burrer R, Buchmeier MJ, Wolfe T, Ting JP, Feuer R, Iglesias A, von Herrath $M G$ : Exacerbated pathology of viral encephalitis in mice with central nervous system-specific autoantibodies. Am J Pathol 2007, 170:557-566.

33. Urich E, Gutcher I, Prinz M, Becher B: Autoantibody-mediated demyelination depends on complement activation but not activatory Fc-receptors. Proc Natl Acad Sci U S A 2006, 103:18697-18702.

34. Piddlesden SJ, Lassmann H, Zimprich F, Morgan BP, Linington C: The demyelinating potential of antibodies to myelin oligodendrocyte glycoprotein is related to their ability to fix complement. Am J Pathol 1993, 143:555-564

35. Nataf S, Carroll SL, Wetsel RA, Szalai AJ, Barnum SR: Attenuation of experimental autoimmune demyelination in complement-deficient mice. $\mathrm{J}$ Immunol 2000, 165:5867-5873.

36. Calida DM, Constantinescu C, Purev E, Zhang GX, Ventura ES, Lavi E, Rostami A: Cutting edge: $\mathrm{C} 3$, a key component of complement activation, is not required for the development of myelin oligodendrocyte glycoprotein peptide-induced experimental autoimmune encephalomyelitis in mice. $\mathrm{J}$ Immunol 2001, 166:723-726.

37. Davoust N, Nataf S, Reiman R, Holers MV, Campbell IL, Barnum SR: Central nervous system-targeted expression of the complement inhibitor sCrry prevents experimental allergic encephalomyelitis. J Immunol 1999, 163:6551-6556.

38. Boos LA, Szalai AJ, Barnum SR: Murine complement C4 is not required for experimental autoimmune encephalomyelitis. Glia 2005, 49:158-160.

39. Reiman R, Gerard C, Campbell IL, Barnum SR: Disruption of the C5a receptor gene fails to protect against experimental allergic encephalomyelitis. Eur J Immunol 2002, 32:1157-1163.

40. Nandakumar KS, Johansson BP, Björck L, Holmdahl R: Blocking of experimental arthritis by cleavage of IgG antibodies in vivo. Arthritis Rheum 2007, 56:3253-3260.

41. Nandakumar KS, Collin M, Olsen A, Nimmerjahn F, Blom AM, Ravetch JV, Holmdahl R: Endoglycosidase treatment abrogates IgG arthritogenicity: importance of IgG glycosylation in arthritis. Eur J Immunol 2007, 37:2973-2982

42. Collin M, Shannon O, Björck L: IgG glycan hydrolysis by a bacterial enzyme as a therapy against autoimmune conditions. Proc Natl Acad SCi U S A 2008, 105:4265-4270.

43. Allhorn M, Briceno JG, Baudino L, Lood C, Olsson ML, Izui S, Collin M: The lgG-specific endoglycosidase EndoS inhibits both cellular and complement-mediated autoimmune hemolysis. Blood 2010, 115:5080-5088.

44. van Timmeren MM, van der Veen BS, Stegeman CA, Petersen AH, Hellmark T, Collin M, Heeringa P: IgG glycan hydrolysis attenuates ANCA-mediated glomerulonephritis. J Am Soc Nephrol 2010, 21:1103-1114.

45. Benkhoucha M, Santiago-Raber ML, Schneiter G, Chofflon M, Funakoshi H, Nakamura T, Lalive PH: Hepatocyte growth factor inhibits CNS autoimmunity by inducing tolerogenic dendritic cells and CD25 + Foxp3 + regulatory T cells. Proc Natl Acad Sci U S A 2010, 107:6424-6429.

46. Weber MS, Benkhoucha M, Lehmann-Horn K, Hertzenberg D, Sellner J, Santiago-Raber ML, Chofflon M, Hemmer B, Zamvil SS, Lalive PH: Repetitive pertussis toxin promotes development of regulatory $T$ cells and prevents central nervous system autoimmune disease. PLoS One 2010, 5:e16009.

47. Collin M, Olsen A: Effect of SpeB and EndoS from Streptococcus pyogenes on human immunoglobulins. Infect Immun 2001, 69:7187-7189.

48. Nikic I, Merkler D, Sorbara C, Brinkoetter M, Kreutzfeldt M, Bareyre FM, Bruck W, Bishop D, Misgeld T, Kerschensteiner M: A reversible form of axon damage in experimental autoimmune encephalomyelitis and multiple sclerosis. Nat Med 2011, 17:495-499.

49. Villar LM, Sadaba MC, Roldan E, Masjuan J, Gonzalez-Porque P, Villarrubia N, Espino M, Garcia-Trujillo JA, Bootello A, Alvarez-Cermeno JC: Intrathecal synthesis of oligoclonal IgM against myelin lipids predicts an aggressive disease course in MS. J Clin Invest 2005, 115:187-194.

50. Avasarala JR, Cross AH, Trotter JL: Oligoclonal band number as a marker for prognosis in multiple sclerosis. Arch Neurol 2001, 58:2044-2045.

51. Genain $C P$, Nguyen $M H$, Letvin NL, Pearl R, Davis RL, Adelman M, Lees MB, Linington C, Hauser SL: Antibody facilitation of multiple sclerosis-like lesions in a nonhuman primate. J Clin Invest 1995, 96:2966-2974.

52. Linington C, Bradl M, Lassmann H, Brunner C, Vass K: Augmentation of demyelination in rat acute allergic encephalomyelitis by circulating mouse monoclonal antibodies directed against a myelin/ oligodendrocyte glycoprotein. Am J Pathol 1988, 130:443-454.

53. Marta CB, Oliver AR, Sweet RA, Pfeiffer SE, Ruddle NH: Pathogenic myelin oligodendrocyte glycoprotein antibodies recognize glycosylated epitopes and perturb oligodendrocyte physiology. Proc Natl Acad Sci U S A 2005, 102:13992-13997.

54. Bar-Or A, Fawaz L, Fan B, Darlington PJ, Rieger A, Ghorayeb C, Calabresi PA, Waubant E, Hauser SL, Zhang J, Smith CH: Abnormal B-cell cytokine responses a trigger of T-cell-mediated disease in MS? Ann Neurol 2010, 67:452-461.

55. Warrington AE, Asakura K, Bieber AJ, Ciric B, Van Keulen V, Kaveri SV, Kyle $R A$, Pease $L R$, Rodriguez M: Human monoclonal antibodies reactive to oligodendrocytes promote remyelination in a model of multiple sclerosis. Proc Natl Acad Sci U S A 2000, 97:6820-6825.

56. Oliver AR, Lyon GM, Ruddle NH: Rat and human myelin oligodendrocyte glycoproteins induce experimental autoimmune encephalomyelitis by different mechanisms in C57BL/6 mice. J Immunol 2003, 171:462-468.

57. Liu G, Muili KA, Agashe W, Lyons JA: Unique $B$ cell responses in $B$ cell-dependent and B cell-independent EAE. Autoimmunity 2012, 45:199-209.

58. Marta CB, Bansal R, Pfeiffer SE: Microglial Fc receptors mediate physiological changes resulting from antibody cross-linking of myelin oligodendrocyte glycoprotein. J Neuroimmunol 2008, 196:35-40.

59. Breij EC, Heijnen P, Vloet R, Saito T, van de Winkel JG, Dijkstra CD, Amor S, Verbeek S: The FcRgamma chain is not essential for induction of experimental allergic encephalomyelitis (EAE) or anti-myelin antibody-mediated exacerbation of EAE. J Neuropathol Exp Neurol 2005, 64:304-311.

60. Abdul-Majid KB, Stefferl A, Bourquin C, Lassmann H, Linington C, Olsson T, Kleinau S, Harris RA: Fc receptors are critical for autoimmune inflammatory damage to the central nervous system in experimental autoimmune encephalomyelitis. Scand J Immunol 2002, 55:70-81.

61. Szalai AJ, Hu X, Raman C, Barnum SR: Requirement of the Fc receptor common gamma-chain for gamma delta T cell-mediated promotion of murine experimental autoimmune encephalomyelitis. Eur J Immunol 2005, 35:3487-3492.

62. Linington C, Morgan BP, Scolding NJ, Wilkins P, Piddlesden S, Compston $\mathrm{DA}$ : The role of complement in the pathogenesis of experimental allergic encephalomyelitis. Brain 1989, 112:895-911.

63. Lucchinetti CF, Mandler RN, McGavern D, Bruck W, Gleich G, Ransohoff RM, Trebst C, Weinshenker B, Wingerchuk D, Parisi JE, Lassmann $\mathrm{H}$ : A role for humoral mechanisms in the pathogenesis of Devic's neuromyelitis optica. Brain 2002, 125:1450-1461.

64. Liu WT, Vanguri P, Shin ML: Studies on demyelination in vitro: the requirement of membrane attack components of the complement system. J Immunol 1983, 131:778-782.

65. Sanders ME, Alexander EL, Koski CL, Shin ML, Sano Y, Frank MM, Joiner KA: Terminal complement complexes (SC5b-9) in cerebrospinal fluid in autoimmune nervous system diseases. Ann N Y Acad Sci 1988, 540:387-388.

66. Sellebjerg F, Jaliashvili I, Christiansen M, Garred P: Intrathecal activation of the complement system and disability in multiple sclerosis. J Neurol Sci 1998, 157:168-174.

67. Linington C, Lassmann H, Morgan BP, Compston DA: Immunohistochemical localisation of terminal complement component C9 in experimental allergic encephalomyelitis. Acta Neuropathol 1989, 79:78-85.

68. Allhorn M, Olin Al, Nimmerjahn F, Collin M: Human IgG/Fc gamma R interactions are modulated by streptococcal lgG glycan hydrolysis. PLOS One 2008, 3:e1413.

69. Ephrem A, Chamat S, Miquel C, Fisson S, Mouthon L, Caligiuri G, Delignat S, Elluru S, Bayry J, Lacroix-Desmazes S, Cohen JL, Salomon BL, Kazatchkine $M D$, Kaveri SV, Misra N: Expansion of CD4 $+C D 25+$ regulatory T cells by intravenous immunoglobulin: a critical factor in controlling experimental autoimmune encephalomyelitis. Blood 2008, 111:715-722.

70. Elovaara I, Kuusisto H, Wu X, Rinta S, Dastidar P, Reipert B: Intravenous immunoglobulins are a therapeutic option in the treatment of multiple sclerosis relapse. Clin Neuropharmacol 2011, 34:84-89.

71. Samuelsson A, Towers TL, Ravetch JV: Anti-inflammatory activity of IVIG mediated through the inhibitory Fc receptor. Science 2001, 291:484-486. 
72. Weinshenker BG, O'Brien PC, Petterson TM, Noseworthy JH, Lucchinetti CF, Dodick DW, Pineda AA, Stevens LN, Rodriguez M: A randomized trial of plasma exchange in acute central nervous system inflammatory demyelinating disease. Ann Neurol 1999, 46:878-886.

73. Keegan M, Konig F, McClelland R, Bruck W, Morales Y, Bitsch A, Panitch H, Lassmann H, Weinshenker B, Rodriguez M, Parisi J, Lucchinetti CF: Relation between humoral pathological changes in multiple sclerosis and response to therapeutic plasma exchange. Lancet 2005, 366:579-582.

74. Hauser SL, Waubant E, Arnold DL, Vollmer T, Antel J, Fox RJ, Bar-Or A, Panzara M, Sarkar N, Agarwal S, Langer-Gould A, Smith CH, HERMES Trial Group: B-cell depletion with rituximab in relapsing-remitting multiple sclerosis. N Engl J Med 2008, 358:676-688.

doi:10.1186/1742-2094-9-209

Cite this article as: Benkhoucha et al:: IgG glycan hydrolysis by EndoS

inhibits experimental autoimmune encephalomyelitis. Journal of

Neuroinflammation 2012 9:209.

\section{Submit your next manuscript to BioMed Central and take full advantage of:}

- Convenient online submission

- Thorough peer review

- No space constraints or color figure charges

- Immediate publication on acceptance

- Inclusion in PubMed, CAS, Scopus and Google Scholar

- Research which is freely available for redistribution 